\title{
Regional estimation of Curie-point depths and succeeding geothermal parameters from recently acquired high-resolution aeromagnetic data of the entire Bida Basin, north-central Nigeria
}

\author{
Levi I. Nwankwo ${ }^{1}$ and Abayomi J. Sunday ${ }^{2}$ \\ ${ }^{1}$ Department of Geophysics, University of Ilorin, PMB 1515, Ilorin, Nigeria \\ ${ }^{2}$ Physics Unit, Department of Science Laboratory Technology, Kwara State Polytechnic, Ilorin, Nigeria
}

Correspondence to: Levi I. Nwankwo (levinwankwo@yahoo.com)

Received: 5 December 2016 - Revised: 28 February 2017 - Accepted: 3 March 2017 - Published: 24 March 2017

\begin{abstract}
A regional estimation of Curie-point depths (CPDs) and succeeding geothermal gradients and subsurface crustal heat flow has been carried out from the spectral centroid analysis of the recently acquired highresolution aeromagnetic (HRAM) data of the entire Bida Basin in north-central Nigeria. The HRAM data were divided into 28 overlapping blocks, and each block was analysed to obtain depths to the top, centroid, and bottom of the magnetic sources. The depth values were then used to assess the CPD, geothermal gradient, and subsurface crustal heat flow in the basin. The result shows that the CPD varies between 15.57 and $29.62 \mathrm{~km}$ with an average of $21.65 \mathrm{~km}$, the geothermal gradient varies between 19.58 and $37.25^{\circ} \mathrm{C} \mathrm{km}^{-1}$ with an average of $27.25^{\circ} \mathrm{C} \mathrm{km}^{-1}$, and the crustal heat flow varies between 48.41 and $93.12 \mathrm{~mW} \mathrm{~m}^{-2}$ with an average of $68.80 \mathrm{~mW} \mathrm{~m}^{-2}$. Geodynamic processes are mainly controlled by the thermal structure of the Earth's crust; therefore this study is important for appraisal of the geo-processes, rheology, and understanding of the heat flow variations in the Bida Basin, north-central Nigeria.
\end{abstract}

\section{Introduction}

This study aims at quantitative estimation of regional Curiepoint depth (CPD) and succeeding geothermal structures, namely geothermal gradients and subsurface crustal heat flow anomalies, in the whole of Bida Basin in north-central Nigeria using the spectral centroid analysis of the recently acquired high-resolution airborne magnetic (HRAM) data. The HRAM surveys were carried out by Fugro Airborne Survey Limited for the Nigerian Geological Survey Agency (NGSA) between 2004 and 2009. Acquisition, processing, and compilation of the HRAM data were jointly financed by the Federal Government of Nigeria and the World Bank as part of the Sustainable Management for Mineral Resources Project (SMMRP) in Nigeria.

Several studies have shown that regional magnetic data can be used extensively to determine the thermal structure of the Earth's crust in various geologic environments (Spec- tor and Grant, 1970; Bhattacharyya and Leu, 1975, 1977; Byerly and Stolt, 1977; Blakely and Hassanzadeh, 1981; Okubo et al., 1985, 2003; Blakely, 1988, 1995; Maus et al., 1997; Tanaka et al., 1999; Chiozzi et al., 2005; Eppelbaum and Pilchin, 2006; Ross et al., 2006; Ravat et al., 2007; Trifonova et al., 2009; Gabriel et al., 2011, 2012; Bansal et al., 2011, 2013, 2016; Nabi, 2012; Hsieh et al., 2014; Nwankwo and Shehu, 2015; etc.). For example, dominant magnetic minerals in the Earth's crust pass from ferromagnetic to paramagnetic state at temperature, commonly called Curie-point temperature (CPT). Magnetite $\left(\mathrm{Fe}_{3} \mathrm{O}_{4}\right)$ is the most common magnetic material in igneous rocks and has an approximate CPT value of $580^{\circ} \mathrm{C}$ (Stacey, 1977). At temperature above $\mathrm{CPT}$, the thermal agitation causes the spontaneous alignment of the various domains in the mineral to be destroyed (or randomized) to the extent that the ferromagnetic minerals become totally paramagnetic (Langel and Hinze, 1998). 


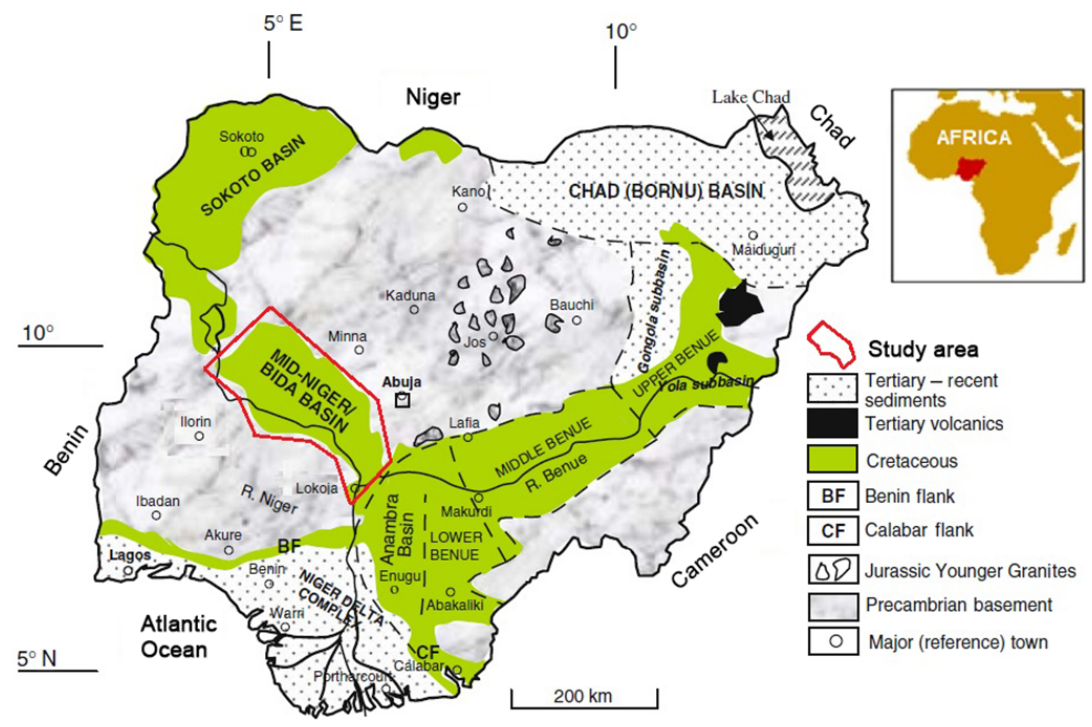

Figure 1. Geological map of Nigeria showing location of the Bida Basin (after Nwankwo and Shehu, 2009).

Therefore CPD, which is defined as the depth at which CPT is reached within the subsurface, can be considered as an index of depth to the bottom of magnetic sources (DBMS) and can consequently be calculated from geomagnetic anomalies (Bansal et al., 2011, 2013; Hsieh et al., 2014). However, in some circumstances DBMS can be caused by contrasts in lithology instead of CPT and may not necessarily coincide with CPT in detail (Bansal et al., 2011; Trifonova et al., 2009). For instance, Trifonova et al. (2009) opined that even if the spectral method provides a good estimate of DBMS there is no assurance that it represents the CPD. They reasoned that a variety of geologic reasons exist for truncated magnetic sources that are unrelated to crustal temperatures; for example, a sequence of relatively non-magnetic sediments below young volcanic material may limit the depth of magnetic sources regardless of the CPT, and another reason is the variety of magnetic minerals like titanomagnetite $\left(\mathrm{Fe}_{3-x} \mathrm{Ti}_{x} \mathrm{O}_{4}\right)$. Titanomagnetite is the most important iron oxide in crustal magnetic sources; it has a CPT that is strongly influenced by the amount of titanium and ranges from 150 to $580^{\circ} \mathrm{C}$. In some geologic environments, alloys of iron with CPTs in excess of $620^{\circ} \mathrm{C}$ may be significant contributors to magnetic anomalies. In spite of these limitations, many studies (Tanaka et al., 1999; Trifonova et al., 2009; Bansal et al., 2011; Hsieh et al., 2014; etc.) have reasonably used DBMS as an estimate of CPD and therefore serve as a proxy for temperature at depth. Again, Trifonova et al. (2009) pointed out that several studies have identified low-titanium titanomagnetite as the dominant magnetic phase, and CPTs at these depths are estimated to be between 575 and $600^{\circ} \mathrm{C}$. This confirms the estimated value of $580^{\circ} \mathrm{C}$ by Stacey (1977) as the case in this study. Another important justification is that DBMS/CPD estimations can similarly be used to complement geothermal data in re- gions where deep boreholes are unavailable (Chapman and Furlong, 1992; Ross et al., 2006; Bansal et al., 2011, 2013).

The Bida Basin is the least studied of all Nigeria's inland frontier basins. To date, the basin has no information on seismicity, no exploratory wells have penetrated its sequences, and deep crustal data are limited (Obaje et al., 2015). Therefore, this present work is expected to contribute immensely to a better understanding of the geothermal structures and geodynamic processes in the entire Bida Basin in north-central Nigeria.

\section{Location and geology of the study area}

The Bida Basin (also known as the Middle Niger Basin or Nupe Basin) is an elongated NW-SE-trending depression perpendicular to the main axis of the Benue Basin of Nigeria. The entire basin (Fig. 1) is bounded by latitudes $8^{\circ} 00^{\prime} \mathrm{N}$ and $10^{\circ} 30^{\prime} \mathrm{N}$ and longitudes $4^{\circ} 30^{\prime} \mathrm{E}$ and $7^{\circ} 30^{\prime} \mathrm{E}$, and it covers an area of approximately $90750 \mathrm{~km}^{2}$.

The geology of the Bida Basin is believed to be a gentle down-warped shallow trough filled with CampanianMaastrichtian marine to fluviatile strata. The strata are also believed to be more than $300 \mathrm{~m}$ thick (Adeleye, 1976). Those with marine affinity, the limestones, often form cappings (under variable thickness of laterites) to the means of the basin. Some form prominent intermediate breaks of slope along the mesa walls. The buried basement complex probably has a high relief, and the sedimentary formations have been shown to be about $2 \mathrm{~km}$ thick (Obaje et al., 2015) with a constituted post-tectonic molasse facies and thin marine strata, which are all unfolded.

The basin might also be regarded as the north-western extension of the Anambra Basin, which is found in the southeast, both of which were major depocentres during the sec- 


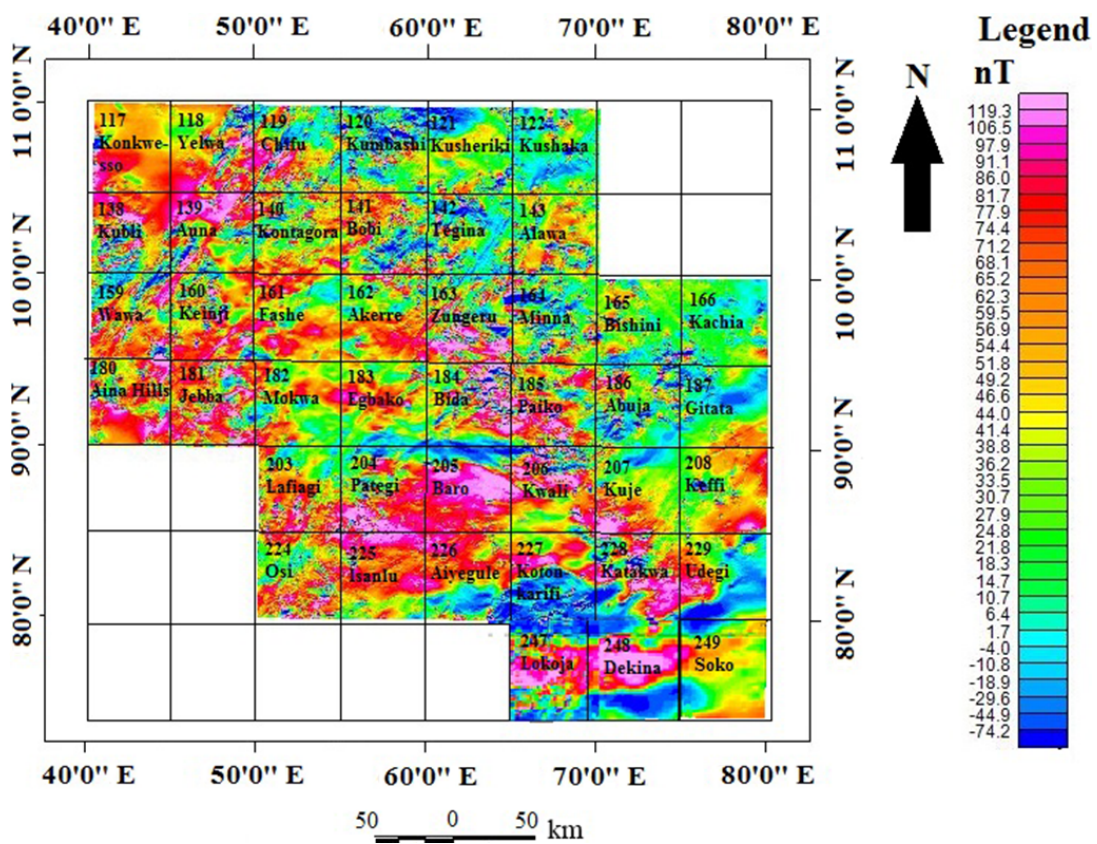

Figure 2. Residual total magnetic intensity map of the entire Bida Basin with superimposed federal survey half-degree sheets and showing major towns flown over. A constant TMI value of $33000 \mathrm{nT}$ was removed.

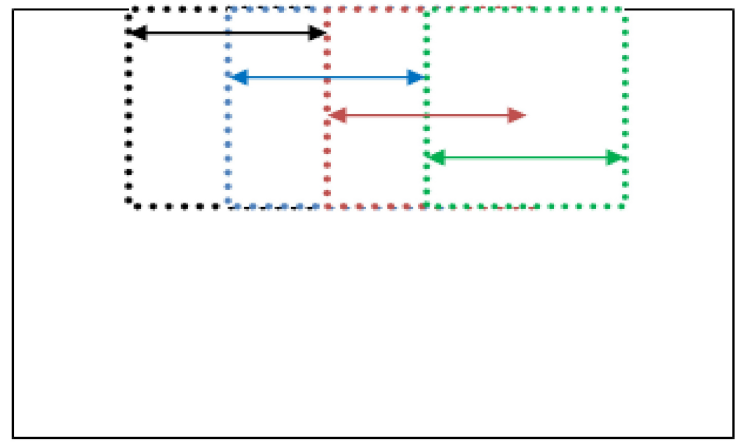

Figure 3. Sketch of procedure for achieving overlapping blocks.

ond major sedimentary cycle of southern Nigeria in the Upper Cretaceous (Obaje, 2009).

The stratigraphy of the basin consists of mainly Patti, Lokoja, and Agbaja formations (Ikumbur et al., 2013). According to Akande et al. (2005), Patti Formation is the only stratigraphic unit containing carbonaceous shale in the basin and is sandwiched between the older CampanianMaastrichtian Lokoja Formation - which contains conglomerates, sandstones, and claystones - and the younger Agbaja Formation, which comprises mostly ironstones.

Tectonically, rift hypothesis has been proposed as the possible origin and evolution of the basin (Kogbe et al., 1983). Some researchers have inferred that the rifting in the basin started in the Upper Cretaceous and that the process started initially from the Benue Trough in the early Cretaceous and eventually spread to other rifted neighbouring basins in the Cretaceous period (Kogbe et al., 1983).

\section{Calculation of Curie-point depth, geothermal gradient, and heat flow}

Calculations of DBMS, which is commonly construed as the Curie-point depth, are made using diverse methods (Spector and Grant, 1970; Shuey et al., 1977; Bhattacharyya and Leu, 1975, 1977; Okubo et al., 1985; Tanaka et al., 1999; Maus and Dimri, 1996; Finn and Ravat, 2004; Ravat et al., 2007; Bansal et al., 2013), namely the spectral-peak method (Spector and Grant, 1970; Shuey et al., 1977), the centroid method (Bhattacharyya and Leu, 1975, 1977; Okubo et al., 1985; Tanaka et al., 1999), the scaling spectral or power-law correction method (Maus and Dimri, 1996), forward modelling of the spectral-peak method (Finn and Ravat, 2004; Ravat et al., 2007), and the modified-centroid fractal method (Bansal et al., 2011; Nwankwo, 2015), among others. The conventional centroid method is used in this work for the reason that it gives better estimates with fewer depth errors compared to earlier methods (Ravat et al., 2007).

The mathematical models of the centroid method are based on the examination of the shape of isolated magnetic anomalies introduced by Bhattacharyya and Leu $(1975,1977)$ and the study of the statistical properties of magnetic ensembles by Spector and Grant (1970). Blakely (1995) subsequently introduced power spectral density of total magnetic field, $\phi_{\Delta T}\left(k_{x}, k_{y}\right)$, as 

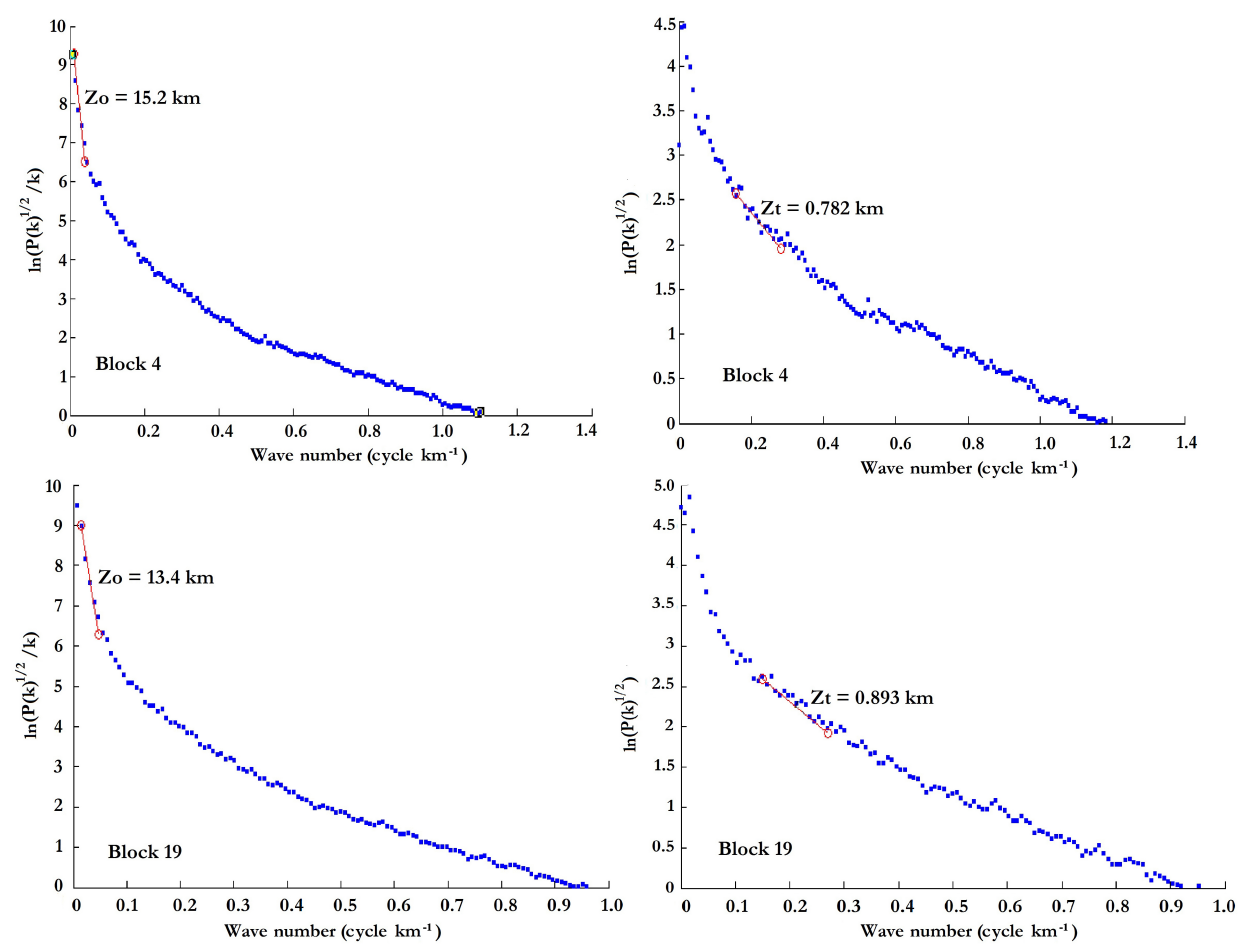

Figure 4. Azimuthally averaged power spectral plots for blocks 4 and 19.

$$
\begin{gathered}
\phi_{\Delta T}\left(k_{x}, k_{y}\right)=\phi_{M}\left(k_{x}, k_{y}\right) \cdot 4 \pi^{2} C_{M}^{2}\left|\theta_{M}\right|^{2}\left|\theta_{\mathrm{f}}\right|^{2} \\
e^{-2|k| Z_{\mathrm{t}}}\left(1-e^{-2|k|\left(Z_{\mathrm{b}}-Z_{\mathrm{t}}\right)}\right)^{2},
\end{gathered}
$$

where $k_{x}$ and $k_{y}$ are wave numbers in $x$ and $y$ direction, $\phi_{M}\left(k_{x}, k_{y}\right)$ is the power spectra of the magnetization, $C_{M}$ is a constant, $\theta_{M}$ and $\theta_{\mathrm{f}}$ are factors for magnetization direction and geomagnetic field direction, and $Z_{\mathrm{b}}$ and $Z_{\mathrm{t}}$ are depths to bottom and top of magnetic layer respectively.

If the layer's magnetization, $M(x, y)$, is a random function of $x, y$, it implies that $\phi_{M}\left(k_{x}, k_{y}\right)$ is a constant, and therefore the azimuthally averaged power spectrum, $\phi(|k|)$, would be given as

$\phi(|k|)=A e^{-2|k| Z_{\mathrm{t}}}\left(1-e^{-2|k|\left(Z_{\mathrm{b}}-Z_{\mathrm{t}}\right)}\right)^{2}$.

The depth to the top of the magnetic source is therefore derived from the slope of the high-wave-number portion of the power spectrum as

$\ln \left(P(k)^{1 / 2}\right)=A-|k| Z_{\mathrm{t}}$,

where $P(k)$ is the azimuthally averaged power spectrum, $k$ is the wave number $\left(2 \pi \mathrm{km}^{-1}\right), A$ is a constant, and $Z_{\mathrm{t}}$ is the depth to the top of magnetic sources.

The centroid depth of magnetic sources can also be calculated from the low-wave-number portion of the wavenumber-scaled power spectrum as (Tanaka et al., 1999)

$\ln \left(P(k)^{1 / 2} / k\right)=B-|k| Z_{o}$, where $B$ is a constant and $Z_{o}$ is the centroid depth of magnetic sources.

The depth to the bottom of the magnetic source $\left(Z_{\mathrm{b}}\right)$ can subsequently be obtained from the relation (Okubo et al., 1985)

$Z_{\mathrm{b}}=2 Z_{o}-Z_{\mathrm{t}}$

Using the depth to the bottom of magnetic sources $\left(Z_{\mathrm{b}}\right)$, the geothermal gradient $(\mathrm{d} T / \mathrm{d} z)$ can be estimated as (Tanaka et al., 1999; Ross et al., 2006)

$\left(\frac{\mathrm{d} T}{\mathrm{~d} z}\right)=\left(\frac{\theta_{\mathrm{c}}}{Z_{\mathrm{b}}}\right)$,

where $\theta_{\mathrm{c}}$ is the Curie temperature.

Next, using $Z_{\mathrm{b}}$ and $\mathrm{d} T / \mathrm{d} z$, the heat flow $\left(q_{z}\right)$ can similarly be estimated as (Okubo et al., 1985)

$q_{z}=-\sigma\left(\frac{\theta_{\mathrm{c}}}{Z_{\mathrm{b}}}\right)=-\sigma\left(\frac{\mathrm{d} T}{\mathrm{~d} z}\right)$,

where $\sigma$ is thermal conductivity. Thermal conductivity of $2.5 \mathrm{~W} \mathrm{~m}^{-1}{ }^{\circ} \mathrm{C}^{-1}$ as the average for igneous rocks and a Curie temperature of $580^{\circ} \mathrm{C}$ (Stacey, 1977; Trifonova et al., 2009) are used as standard in this work.

\section{Data acquisition and analysis}

The regional airborne magnetic surveys over the entire Bida Basin and adjoining areas were carried out using 3 Scintrex 


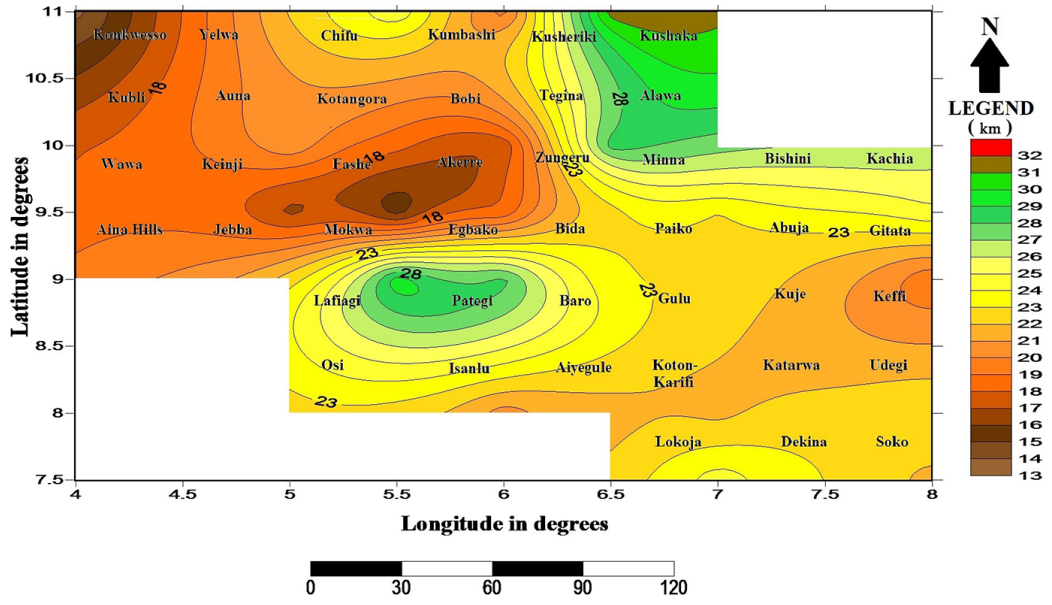

Figure 5. CPD map of the study area.

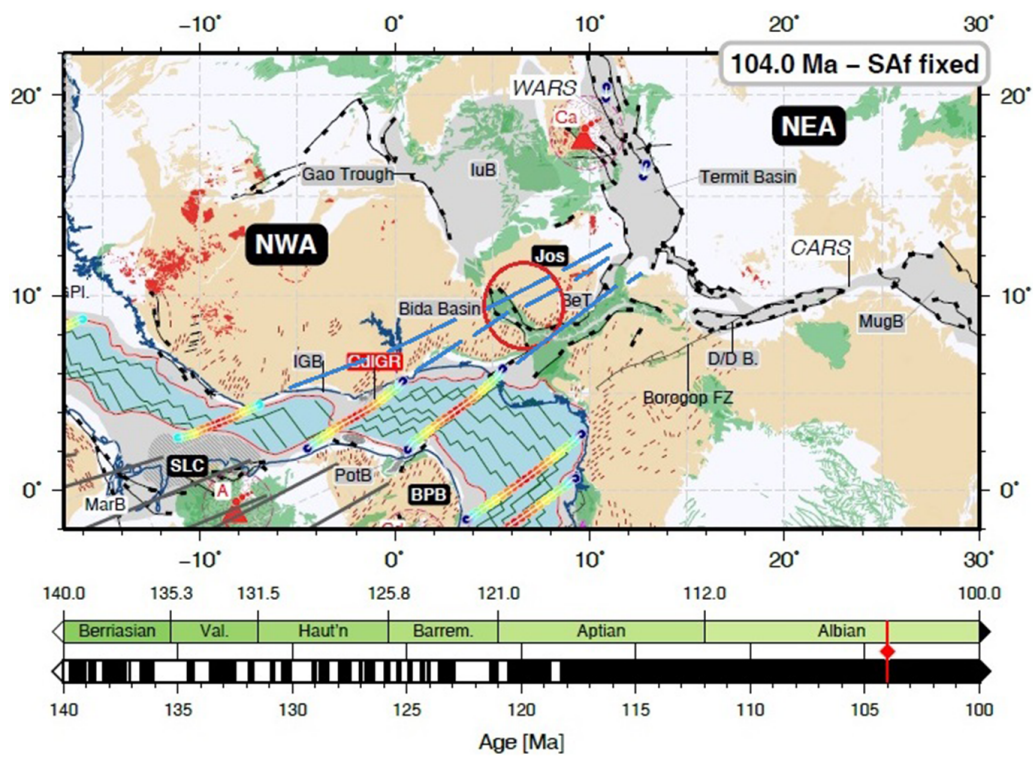

Figure 6. West African Rift System (WARS) and Central African Rift System (CARS) (after Heine et al., 2013). Red circle indicates position of the Bida Basin with extensions of inferred major fracture zones - St Paul, Romanche, and Chain drawn with broken blue lines. These extensions had been suggested by Ajakaiye et al. (1991).

CS-3 cesium vapour magnetometers with a data recording interval of $0.1 \mathrm{~s}$ by means of fixed-wing aircrafts. The aircrafts were flown at mean terrain clearance of $80 \mathrm{~m}$ with $500 \mathrm{~m}$ line spacing and nominal tie-line spacing of $2 \mathrm{~km}$. The flight line and tie-line trends were 135 and $45^{\circ}$ respectively. The resulting magnetic data were published as digital half-degree HRAM intensity maps by the NGSA.

Forty-three new HRAM maps (sheet number 117-122, 138-143, 159-166, 180-187, 203-208, and 224-229) on a scale of $1: 100000$, covering a total area of $130075 \mathrm{~km}^{2}$, were used in this work. All data, covering the entire Bida Basin and adjoining areas, were procured from NGSA as a composite residual total magnetic field intensity (RTMI) map (Fig. 2). Regional correction, which was based on the International Geomagnetic Reference Field (IGRF - 11) derived to spherical harmonic degree 13 , was carried out by the NGSA prior to the publication of the map.

The composite residual map was then divided into 28 overlapping square blocks (Fig. 3), for the purpose of spectral analysis. Each block covers a square area of $200 \mathrm{~km} \times 200 \mathrm{~km}$. Since magnetic source bodies having bases deeper than window length $/ 2 \pi$ may not be properly resolved by the spectral method (Shuey et al., 1977), a window length of $200 \mathrm{~km}$ is found to be suitable in this study. 


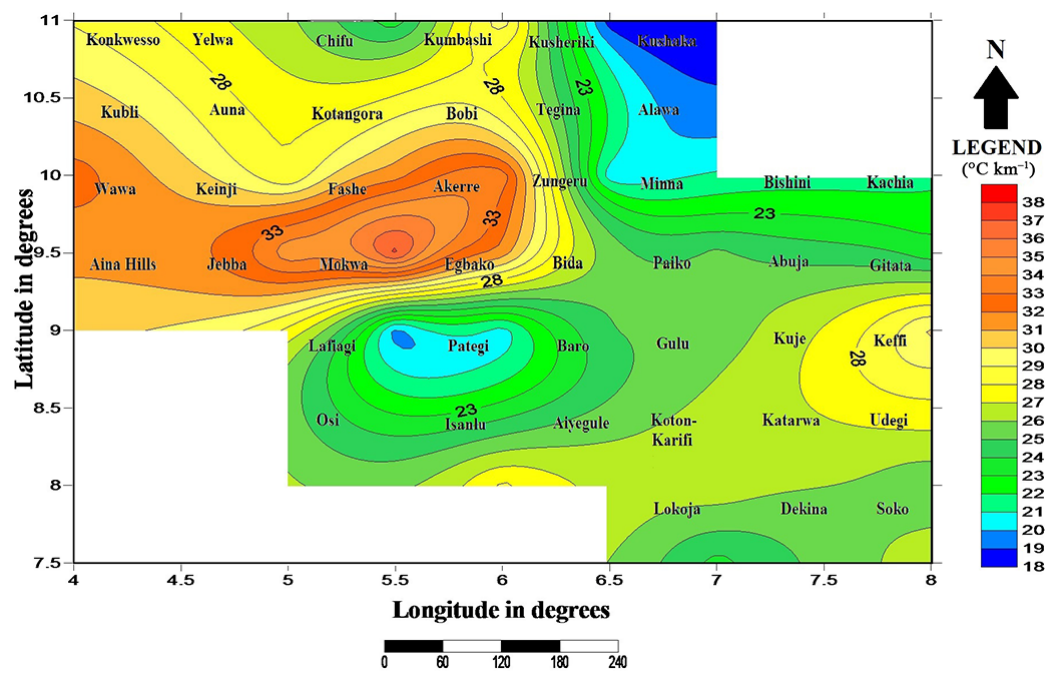

Figure 7. Geothermal gradient map of the study area.

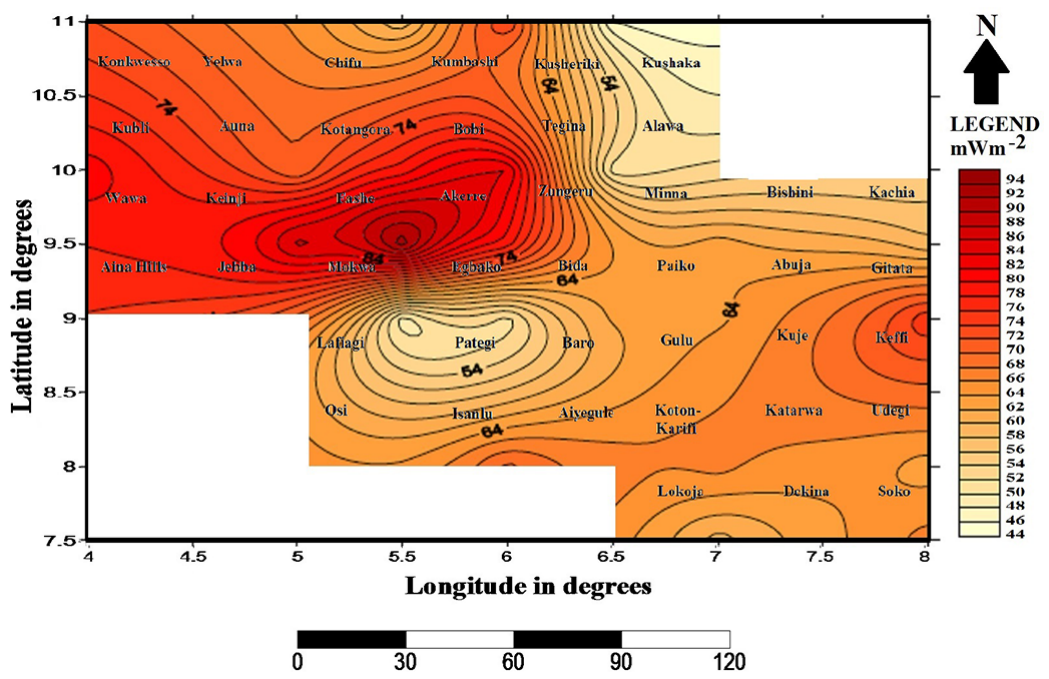

Figure 8. Heat flow map of the study area.

\section{Results and discussions}

Azimuthally averaged power and wave-number-scaled power spectra for each of the 28 overlapping blocks were calculated and used to estimate the DBMS, which of course serve as a proxy for CPDs. As typical examples, blocks 5 and 20 are shown in Fig. 4. The right-hand side of the figure shows the slope of the high-wave-number portion of the spectra, which leads to the estimation of the depth to the top of magnetic sources $\left(Z_{\mathrm{t}}\right)$, while the left-hand side shows the slope of the lower-wave-number part of the wave-number-scaled spectra, which leads to the estimation of centroid depth $\left(Z_{o}\right)$.

The estimated results are shown in Table 1. The table shows that the estimated CPD varies from 15.57 to $29.62 \mathrm{~km}$ with an average of $21.65 \mathrm{~km}$. The CPD isotherm map for the Bida Basin is consequently shown in Fig. 5. CPD varies greatly with different geological settings (Tanaka et al., 1999; Salk et al., 2005). Tanaka et al. (1999), after a compilation of CPD results from several researchers across the globe, inferred that volcanic, tectonic, and associated geodynamic environments have CPD shallower than $10 \mathrm{~km}$, while CPDs ranging between 15 and $25 \mathrm{~km}$ are as a result of island arcs and ridges, and deeper than $25 \mathrm{~km}$ in plateaus and trenches. Figure 5 also shows that the CPD values in the Bida Basin trend mostly in the NE-SW direction, with the shallowest portion (less than $15 \mathrm{~km}$ ) in the north-western part of the basin; the CPD extends and deepens both north-eastward and south-eastward in the basin, with its deepest depth (about $32 \mathrm{~km}$ ) in the north-eastern parts.

Previous studies have shown that two major regional fault lines (namely St Paul and Romanche) are likely to have traversed the basin; these are believed to be extensions of the 
Table 1. Estimated Curie-point depths and succeeding geothermal parameters.

\begin{tabular}{|c|c|c|c|c|c|c|c|}
\hline Blocks & $\begin{array}{l}\text { Long } \\
\left({ }^{\circ} \mathrm{E}\right)^{\mathrm{a}}\end{array}$ & $\begin{array}{r}\text { Lat } \\
\left({ }^{\circ} \mathrm{N}\right)^{\mathrm{a}}\end{array}$ & $\begin{array}{l}\text { Depth to the } \\
\text { top } Z_{\mathrm{t}}(\mathrm{km})\end{array}$ & $\begin{array}{r}\text { Centroid depth } \\
Z_{o}(\mathrm{~km})\end{array}$ & $\begin{array}{l}\text { Depth to bottom } \\
\qquad Z_{\mathrm{b}}(\mathrm{km})^{\mathrm{b}}\end{array}$ & $\begin{array}{r}\text { Geothermal gradient } \\
\left({ }^{\circ} \mathrm{C} \mathrm{km}^{-1}\right)\end{array}$ & $\begin{array}{r}\text { Heat flow } \\
\left(\mathrm{mW} \mathrm{m}^{-2}\right)\end{array}$ \\
\hline 1 & 5.00 & 10.50 & $1.67 \pm 0.01$ & $11.90 \pm 0.05$ & $22.13 \pm 0.100$ & $26.21 \pm 0.119$ & $65.52 \pm 0.119$ \\
\hline 2 & 5.50 & 10.50 & $0.84 \pm 0.03$ & $12.80 \pm 0.01$ & $24.76 \pm 0.036$ & $23.43 \pm 0.034$ & $58.57 \pm 0.034$ \\
\hline 3 & 6.00 & 10.50 & $1.22 \pm 0.11$ & $10.40 \pm 0.13$ & $19.58 \pm 0.282$ & $29.62 \pm 0.427$ & $74.06 \pm 0.427$ \\
\hline 4 & 6.50 & 10.50 & $0.78 \pm 0.05$ & $15.20 \pm 0.02$ & $29.62 \pm 0.064$ & $19.58 \pm 0.042$ & $48.95 \pm 0.042$ \\
\hline 5 & 4.50 & 10.00 & $1.76 \pm 0.08$ & $9.81 \pm 0.11$ & $17.86 \pm 0.234$ & $32.47 \pm 0.426$ & $81.19 \pm 0.426$ \\
\hline 6 & 5.00 & 10.00 & $1.34 \pm 0.01$ & $11.04 \pm 0.05$ & $20.74 \pm 0.100$ & $27.96 \pm 0.135$ & $69.91 \pm 0.135$ \\
\hline 7 & 5.50 & 10.00 & $0.93 \pm 0.02$ & $9.65 \pm 0.06$ & $18.37 \pm 0.122$ & $31.57 \pm 0.209$ & $78.93 \pm 0.209$ \\
\hline 8 & 6.00 & 10.00 & $1.49 \pm 0.12$ & $9.38 \pm 0.07$ & $17.27 \pm 0.184$ & $33.58 \pm 0.359$ & $83.96 \pm 0.359$ \\
\hline 9 & 6.50 & 10.00 & $0.86 \pm 0.11$ & $10.10 \pm 0.02$ & $19.34 \pm 0.117$ & $29.99 \pm 0.182$ & $74.97 \pm 0.182$ \\
\hline 10 & 4.50 & 9.50 & $0.90 \pm 0.03$ & $9.74 \pm 0.12$ & $18.58 \pm 0.242$ & $31.22 \pm 0.406$ & $78.04 \pm 0.406$ \\
\hline 11 & 5.00 & 9.50 & $1.00 \pm 0.01$ & $8.88 \pm 0.07$ & $16.76 \pm 0.140$ & $34.61 \pm 0.290$ & $86.52 \pm 0.290$ \\
\hline 12 & 5.50 & 9.50 & $1.47 \pm 0.04$ & $8.52 \pm 0.03$ & $15.57 \pm 0.072$ & $37.25 \pm 0.173$ & $93.12 \pm 0.173$ \\
\hline 13 & 6.00 & 9.50 & $1.43 \pm 0.13$ & $9.91 \pm 0.05$ & $18.39 \pm 0.164$ & $31.54 \pm 0.281$ & $78.85 \pm 0.281$ \\
\hline 14 & 6.50 & 9.50 & $0.77 \pm 0.05$ & $10.20 \pm 0.02$ & $19.63 \pm 0.064$ & $29.55 \pm 0.096$ & $73.87 \pm 0.096$ \\
\hline 15 & 7.00 & 9.50 & $0.95 \pm 0.03$ & $11.98 \pm 0.10$ & $23.01 \pm 0.202$ & $25.21 \pm 0.222$ & $63.02 \pm 0.222$ \\
\hline 16 & 7.50 & 9.50 & $1.45 \pm 0.05$ & $13.10 \pm 0.13$ & $24.75 \pm 0.265$ & $23.43 \pm 0.251$ & $58.56 \pm 0.251$ \\
\hline 17 & 5.50 & 9.00 & $1.40 \pm 0.01$ & $15.50 \pm 0.09$ & $29.60 \pm 0.180$ & $19.59 \pm 0.119$ & $48.99 \pm 0.119$ \\
\hline 18 & 6.00 & 9.00 & $0.98 \pm 0.02$ & $14.60 \pm 0.04$ & $28.22 \pm 0.082$ & $20.55 \pm 0.060$ & $51.38 \pm 0.060$ \\
\hline 19 & 6.50 & 9.00 & $0.89 \pm 0.08$ & $13.40 \pm 0.07$ & $25.91 \pm 0.161$ & $22.39 \pm 0.139$ & $55.96 \pm 0.139$ \\
\hline 20 & 7.00 & 9.00 & $0.97 \pm 0.05$ & $11.89 \pm 0.02$ & $22.81 \pm 0.064$ & $25.42 \pm 0.071$ & $63.57 \pm 0.071$ \\
\hline 21 & 7.50 & 9.00 & $1.44 \pm 0.11$ & $10.32 \pm 0.04$ & $19.20 \pm 0.136$ & $30.21 \pm 0.214$ & $75.52 \pm 0.214$ \\
\hline 22 & 5.50 & 8.50 & $1.46 \pm 0.01$ & $12.00 \pm 0.11$ & $22.54 \pm 0.220$ & $25.73 \pm 0.251$ & $64.33 \pm 0.251$ \\
\hline 23 & 6.00 & 8.50 & $1.66 \pm 0.03$ & $11.10 \pm 0.03$ & $20.54 \pm 0.067$ & $28.24 \pm 0.092$ & $70.59 \pm 0.092$ \\
\hline 24 & 6.50 & 8.50 & $0.97 \pm 0.05$ & $10.50 \pm 0.10$ & $20.03 \pm 0.206$ & $28.96 \pm 0.298$ & $72.39 \pm 0.298$ \\
\hline 25 & 7.00 & 8.50 & $1.98 \pm 0.01$ & $11.87 \pm 0.07$ & $21.76 \pm 0.140$ & $26.65 \pm 0.172$ & $66.64 \pm 0.172$ \\
\hline 26 & 7.50 & 8.50 & $2.00 \pm 0.01$ & $12.50 \pm 0.09$ & $23.00 \pm 0.180$ & $25.22 \pm 0.198$ & $63.04 \pm 0.198$ \\
\hline 27 & 7.00 & 8.00 & $0.69 \pm 0.04$ & $12.6 \pm 0.04$ & $24.51 \pm 0.089$ & $23.66 \pm 0.086$ & $59.16 \pm 0.086$ \\
\hline 28 & 7.50 & 8.00 & $0.72 \pm 0.13$ & $11.2 \pm 0.05$ & $21.68 \pm 0.164$ & $26.75 \pm 0.202$ & $66.88 \pm 0.202$ \\
\hline Average & & & $1.22 \pm 0.05$ & $11.43 \pm 0.06$ & $21.65 \pm 0.146$ & $27.57 \pm 0.198$ & $68.80 \pm 0.198$ \\
\hline
\end{tabular}

${ }^{\mathrm{a}}$ Centre of the blocks; ${ }^{\mathrm{b}}$ corresponds to Curie-point depth.

onshore lineaments in West Africa, which are part of the major weakness in the crust that predates the opening of the Atlantic Ocean, and were reactivated in the early stages of continental rifting (Fig. 6) (Ajakaiye et al., 1991; Buser, 1966). Thus, the relatively low CPD values over the central portion of the basin may be fairly consistent with probable positions of St Paul and Romanche palaeofracture zones.

Table 1 similarly discloses that the geothermal gradients in the basin vary between 19.58 and $37.25^{\circ} \mathrm{C} \mathrm{km}^{-1}$ with an average of $27.25^{\circ} \mathrm{C} \mathrm{km}^{-1}$, while the crustal heat flow varies between 48.41 and $93.12 \mathrm{~mW} \mathrm{~m}^{-2}$ with an average of $68.80 \mathrm{~mW} \mathrm{~m}^{-2}$. Contour maps for the geothermal gradient and heat flow are shown in Figs. 7 and 8 respectively. The geothermal gradient map also exhibits mostly NE-SW trending. The observed major trends are similar to the regional trending faults in the basin. The lowest values for the geothermal gradient were found in the south-western portion of the basin. The north-westward trend of gradient increase was found to result in a maximum value of $42{ }^{\circ} \mathrm{C} \mathrm{km}^{-1}$ in the north-western part. The minimum heat flow value required for considerable generation of geothermal energy is approximately $60 \mathrm{~mW} \mathrm{~m}^{-2}$, whereas values ranging from 80 to $100 \mathrm{~mW} \mathrm{~m}^{-2}$ and above indicate anomalous geothermal conditions (Jessop et al., 1976). Crustal heat flow in the basin also exhibits NE-SW trending, while the derived amounts increase from the central portion towards the north-west, with maximum values above $90 \mathrm{~mW} \mathrm{~m}^{-2}$ observed in the northcentral portion. This portion signifies an anomalous crustal thermal state and, therefore, is recommended for further investigations.

\section{Conclusion}

The newly acquired high-resolution aeromagnetic anomaly data over the Bida Basin, north-central Nigeria, have been analysed to estimate the Curie-point depths, geothermal gradients, and near-surface crustal heat flow. The result shows that the CPD varies between 15.57 and $29.62 \mathrm{~km}$ 
with an average of $21.65 \mathrm{~km}$, the geothermal gradient varies between 19.58 and $37.25^{\circ} \mathrm{C} \mathrm{km}^{-1}$ with an average of $27.25^{\circ} \mathrm{C} \mathrm{km}^{-1}$, and the crustal heat flow varies between 48.41 and $93.12 \mathrm{~mW} \mathrm{~m}^{-2}$ with an average of $68.80 \mathrm{~mW} \mathrm{~m}^{-2}$.

Regions are observed in the basin with shallow Curie-point depths (below $15 \mathrm{~km}$ ) and corresponding high heat flows (above $80 \mathrm{~mW} \mathrm{~m}^{-2}$ ), thus suggesting anomalous geothermal conditions (Jessop et al., 1976). Hence, further detailed studies are recommended in such regions. Finally, oftentimes, direct crustal temperature measurements may not be too feasible for regional studies; hence, the derived geothermal gradients suffice for the entire basin. Moreover, geodynamic processes are mainly controlled by the thermal structure of the Earth's crust; therefore this study is anticipated to contribute significantly to the quantitative appraisal of the geoprocesses, rheology, and understanding of the heat flux variations in the Bida Basin in north-central Nigeria.

Data availability. The data used are not publicly accessible. However, the data could be obtained from the Abuja office of the Nigerian Geological Survey Agency, citing High Resolution Aeromagnetic sheet numbers 117-122, 138-143, 159-166, 180-187, 203208, and 224-229.

Author contributions. Levi I. Nwankwo planned the study, and Abayomi J. Sunday carried it out. Levi I. Nwankwo prepared the manuscript with contributions from Abayomi J. Sunday.

Competing interests. The authors declare that they have no conflict of interest.

Acknowledgements. The authors are grateful to the Nigerian Geological Survey Agency (NGSA) for releasing the HRAM data at a subsidized rate and to the University of Ilorin, Nigeria, for the facilities made available for the research work. The editors and esteemed reviewers are also acknowledged for their time and constructive inputs.

Edited by: H. Rüter

Reviewed by: two anonymous referee

\section{References}

Adeleye, D.: The geology of the middle Niger Basin, Geology of Nigeria, Elizabethan Publishing Company Limited, Lagos, 283287, 1976.

Ajakaiye, D. E., Hall, D. H., Ashiekaa, J. A., and Udensi, E. E.: Magnetic anomalies in the Nigerian continental mass based on aeromagnetic surveys, Tectonophysics, 192, 211-230, 1991.

Akande, S., Ojo, O., and Ladipo, K.: Upper Cretaceous Sequences in the Southern Bida Basin, Nigeria, A Field Guidebook: Mosuro Publishers, Ibadan, 2005.
Bansal, A. R., Gabriel, G., Dimri, V. P., and Krawczyk, C. M.: Estimation of depth to the bottom of magnetic sources by a modified centroid method for fractal distribution of sources: An application to aeromagnetic data in Germany, Geophysics, 76, L11-L22, 2011.

Bansal, A. R., Anand, S. P., Rajaram, M., Rao, V. K., and Dimri, V. P.: Depth to the bottom of magnetic sources (DBMS) from aeromagnetic data of central India using modified centroid method for fractal distribution of sources, Tectonophysics, 603, 155-161, 2013.

Bansal, A. R., Dimri, V. P., Kumar, R., and Anand, S. P.: Curie depth estimation from aeromagnetic for fractal distribution of sources, in: Fractal solutions for Understanding complex Systems in earth Sciences, edited by: Dimri, V. P., Springer International Publishing, Switzerland, doi:10.1007/978-3-319-24675-8_2, 2016.

Bhattacharyya, B. K. and Leu, L. K.: Analysis of magnetic anomalies over Yellowstone National Park: mapping of Curie point isothermal surface for geothermal reconnaissance, J. Geophys. Res., 8, 4461-4465, 1975.

Bhattacharyya, B. K. and Leu, L. K.: Spectral analysis of gravity and magnetic anomalies due to rectangular prismatic bodies, Geophysics, 42, 41-50, 1977.

Blakely, R. J.: Curie temperature isotherm analysis and tectonic implications of aeromagnetic data from Nevada, J. Geophy. Res., 93, 817-832, 1988.

Blakely, R. J.: Potential theory in gravity and magnetic applications, Cambridge University Press, Cambridge, UK, 1995.

Blakely, R. J. and Hassanzadeh, S.: Estimation of depth to magnetic source using maximum entropy power spectra with application to the Peru-Chile trench, Geol. Soc. Am. Mem., 154, 667-681, 1981.

Buser, H.: Paleostructures of Nigeria and adjacent countries, Schweizerbart'sche Verlagsbuchhandlung, Stuttgart, Germany, 1966.

Byerly, P. E. and Stolt, R. H.: An attempt to define the Curie point isotherm in northen and central Arizona, Geophysics, 42, 13941400, 1977.

Chapman, D. S. and Furlong, K. P.: Thermal state of continental lower crust, in: Continental Lower Crust, edited by: Fountain, D. M., Arculus, R., and Kay, R. W., Elsevier Science, Amsterdam, 179-199, 1992.

Chiozzi, P., Matsushima, Y., Okubo, V., Pasquale, M., and Verdoya, M.: Curie-point depth from spectral analysis of magnetic data in central-southern Europe, Phys. Earth Planet. In., 152, 267-276, 2005.

Eppelbaum, L. V. and Pilchin, A. N.: Methodology of Curie discontinuity map development for regions with low thermal characteristics: an example from Israel, Earth Planet. Sc. Lett., 243, 536-551, 2006.

Finn, C. A. and Ravat, D.: Magnetic depth estimates and their potential for constraining crustal composition and heat flow in Antarctica, EOS T. Am. Geophys. Un., 85, Fall meeting Suppl., Abstract T11A-1236, 2004.

Gabriel, G., Bansal, A. R., Dressel, I., Dimri, V. P., and Krawczyk, C. M.: Curie depths estimation in Germany: methodological studies for derivation of geothermal proxies using new magnetic anomaly data, Geophys. Res. Abstr., EGU2011-6938, EGU General Assembly 2011, Vienna, Austria, 2011. 
Gabriel, G., Dressel, I., Vogel, D., and Krawczyk, C. M.: Depths to the bottom of magnetic sources and geothermal prospectivity in southern Germany, First Break, 30, 39-47, 2012.

Heine, C., Zoethout, J., and Muller, R. D.: Kinematics of the South Atlantic rift, Solid Earth, 4, 215-253, 2013.

Hsieh, H., Chen, C., and Yen, H.: Curie point depth from spectral analysis of magnetic data in Taiwan, J. Asian Earth Sci., 90, 2630, 2014.

Ikumbur, E. B., Onwuemesi, A. G., Anakwuba, E. K., Chinwuko, A. I., Usman, A. O., and Okonkwo, C. C.: Spectral Analysis of Aeromagnetic Data over Part of the Southern Bida basin, WestCentral Nigeria, Int. J. Fundament. Phys. Sci., 3, 27-31, 2013.

Jessop, A. M., Habart, M. A., and Sclater, J. G.: The world heat flow data collection 1975. Geothermal Services of Canada, Geotherm. Ser., 50, 55-77, 1976.

Kogbe, C. A., Ajakaiye, D. E., and Matheis, G.: Confirmation of rift structure along the middle- Niger Valley, Nigeria, J. Afr. Earth Sci., 1, 127-131, 1983.

Langel, R. A. and Hinze, W. J.: The magnetic field of the lithosphere: the satellite perspective, Cambridge University Press, Cambridge, UK, 429, 157-158, 1998.

Maus, S. and Dimri, V. P.: Depth estimation from the scaling power spectrum of potential field, Geophys. J. Int., 124, 113-120, 1996.

Maus, S., Gordon, D., and Fairhead, D.: Curie temperature depth estimation using a self-similar magnetization model, Geophys. J. Int., 129, 163-168, 1997.

Nabi, S. H. A.: Curie point depth beneath the Barramiya-Red sea coast area estimated from spectral analysis of aeromagnetic data, J. Asian Earth Sci., 43, 254-266, 2012.

Nwankwo, L. I.: Estimation of depths to the bottom of magnetic sources and ensuing geothermal parameters from aeromagnetic data of Upper Sokoto Basin, Nigeria, Geothermics, 54, 76-81, 2015.

Nwankwo, L. I. and Shehu, A. T.: Evaluation of Curie-point depths, geothermal gradients and near-surface heat flown from highresolution aeromagnetic (HRAM) data of the entire Sokoto Basin, Nigeria, J. Volcanol. Geoth. Res., 305, 45-55, 2015.

Obaje, N. G.: Geology and Mineral Resources of Nigeria, Lecture Notes in Earth Sciences, Springer, Berlin Heidelberg, 2009.
Obaje, N. G., Idris-Nda, A., Goro, A. I., Dantata, S. H., Okoro, A. U., Akpunonu, E. O., and Jatau, S. B.: New assessment for Central Nigeria's Bida basin highlights geological prospects, Oil and Gas Journal, 113, 52-59, 2015.

Okubo, Y., Graff, R. G., Hansen, R. O., Ogawa, K., and Tsu, H.: Curie point depths of the Island of Kyushu and surrounding areas, Geophysics, 53, 481-494, 1985.

Okubo, Y., Matsushima, J., and Correia, A.: Magnetic spectral analysis in Portugal and its adjacent seas, Phys. Chem. Earth, 28, 511-519, 2003.

Ravat, D., Pignatelli, A., Nicolosi, I., and Chiappini, M.: A study of spectral methods of estimating the depth to the bottom of magnetic sources from near-surface magnetic anomaly data, Geophys. J. Int., 169, 421-434, 2007.

Ross, H. E., Blakely, R. J., and Zoback, M. D.: Testing the use of aeromagnetic data for the determination of Curie depth in California, Geophysics, 71, L51-L59, 2006.

Salk, M., Pamukcu, O., and Kaftan, I.: Determination of Curie point dept and heat flow from magsat data of western Anatolia, Journal of Balkan Geophysical Society, 8, 149-160, 2005.

Shuey, R. T., Schellinger, D. K., Tripp, A. C., and Alley, L. B.: Curie depth determination from aeromagnetic spectra, Geophys. J. Roy. Astr. S., 50, 75-101, 1977.

Spector, A. and Grant, F. S.: Statistical models for interpreting aeromagnetic data, Geophysics, 35, 293-302, 1970.

Stacey, F. O.: Physics of the Earth, John Wiley and Sons, New York, 1977.

Tanaka, A. Y., Okubo, Y., and Matsubayashi, O.: Curie point depth based on spectrum analysis of the magnetic anomaly data in East and Southeast Asia, Tectonophysics, 306, 461-470, 1999.

Trifonova, P., Zhelev, Z., Petrova, T., and Bojadgieva, K.: Curie point depth of Bulgarian territory inferred from geomagnetic observations and its correlation with regional thermal structure and seismicity, Tectonophysics, 473, 362-374, 2009. 